\title{
Viewpoints
}

\section{Challenges in the COVID-19 vaccination era: Prioritization of vaccines among essential workers in Mexico}

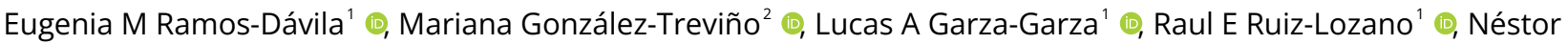 \\ Ibarra-Salazar', Michel F Martinez-Resendez \\ 1 Tecnológico de Monterrey, Monterrey, México, 2 School of Medicine, Universidad Autónoma de Nuevo León, Monterrey, México \\ Keywords: COVID-19, vaccines, health personnel, health policy \\ https://doi.org/10.52872/001c.29054
}

\section{Journal of Global Health Economics and Policy}

Vol. 1, 2021

\begin{abstract}
The coronavirus disease-2019 (COVID-19) pandemic gave rise to a massive global health concern that has placed an unprecedented strain on healthcare systems, education and economy. The recent vaccine roll-out gave humanity a glimpse of hope. However, more than $50 \%$ of the vaccine supply has been acquired by high-income countries, forcing lowand middle-income countries to prioritize who should be vaccinated. In Mexico, the first phase of the vaccination program prioritized healthcare personnel working in front-line COVID-19 public institutions. The second phase was planned for the remaining healthcare workers attending at both COVID and non-COVID areas. The government, however, aiming to reopen schools, decided to vaccinate teachers instead. This raised several concerns, since Mexico tops the ranking of deaths among healthcare workers due to COVID-19 worldwide. Furthermore, the possible framing of vaccines as a political tool has caused commotion among the Mexican people and media, especially since 2021 is the Midterm Election year in Mexico, and the Teachers' Union has historically played an essential role in this matter. Therefore, it is relevant to share the vaccination experience in resource-constrained settings to provide help and advice to reach an optimal strategy and deflate this pandemic.
\end{abstract}

The emergence of the current coronavirus disease 2019 (COVID-19) pandemic has given rise to a massive global health concern that placed an unprecedented strain on healthcare systems and the education and economy of every country. Almost a year later, the approval of different COVID-19 vaccines has given people worldwide a glimmer of hope. However, more than 50\% of the COVID-19 vaccine supply has been acquired by high-income nations, forcing low- and middle-income countries to prioritize specific populations for vaccine administration. ${ }^{1,2}$ For example, despite being a middle-income country, Mexico was ranked as the tenth nation with the highest vaccine acquisition. ${ }^{3}$ Nonetheless, manufacturers' uncertainty of vaccine supplies and delays in production have made the programming and roll-out of vaccines quite complicated.

In Mexico, a technical advisory group (GTAVCovid-19) was formed to design the vaccination strategy. This group proposed prioritizing healthcare workers (starting with all COVID-19 centres, followed by the remaining physicians), densely populated areas with higher mortality rates, and citizens $>50$ years old to receive the vaccine. By vaccinating $20 \%$ of the population, this strategy predicted lowering mortality rates up to $80 \%$ and covering the most vulnerable population sectors. ${ }^{4}$ Nonetheless, the federal government decided to proceed differently, administering vaccines during the first phase only to healthcare personnel working at first line COVID-19 public institutions, excluding COVID-19 private clinics. Furthermore, the second phase, which originally included adults $>60$ years and the rest of the health- care providers, was subsequently modified to reactivate face-to-face education, i.e. healthcare providers were replaced by educational workers, leaving health personnel attending non-COVID-19 areas and all private practices unvaccinated. ${ }^{5}$

The exclusion of the remaining healthcare workers raised several concerns as this population is seven times more likely to present with severe disease than the other essential workers. ${ }^{6}$ Moreover, as of June 2021, Mexico continued to report the world's highest death rate among health personnel due to COVID-19 infection with 3.940 deaths, followed by the United States (1.646) and Peru (1.345). ${ }^{7}$ Most of these infections probably occurred in health providers attending non-COVID-19 areas, which are centres destined to treat any other condition other than COVID-19, since international studies suggest that asymptomatic individuals might be responsible for more than $50 \%$ of transmissions. ${ }^{8}$ Additionally, the lack of specialized personal protective equipment forced it to designate its distribution to institutions attending only COVID-19 patients, thereby leaving nonCOVID-19 hospitals and general practitioners in the outpatient setting without adequate protection. ${ }^{9}$

The suspicion that political motives influence vaccination priorities is prevalent among the Mexican press and media, since 2021 is the Midterm Election year, and the Teachers' Unions has historically played an important role in this matter. Moreover, the organization of vaccination programs in Mexico has historically been the domain of the Secretary of Health, with vaccines being administrated by 
healthcare personnel. For COVID-19, however, this dynamic substantially changed, and vaccines were ordered to be administered by "Servidores de la Nación”, composed of about 23,000 members of the political party in power. Also, several members of the Army were instructed to secure vaccination sites, raising criticism regarding the heavily militarized vaccination brigades. ${ }^{1}$

On the other hand, the struggle for quality and reach of education during the pandemic in low- and middle-income countries should not be underestimated. In Mexico, $43.5 \%$ of homes lack internet access, and as an effort to address this problem and mitigate the possible exacerbation of existing inequalities, ${ }^{10}$ classes are now broadcasted on national T.V. and radio, stretching educational reach to $92.5 \%$ of the population. ${ }^{11}$ Although reopening schools is ideal, attempting to do so by vaccinating teachers may not diminish the spread of the virus since vaccines are tested in terms of mortality or severe disease prevention and have not been proven to reduce transmission yet. ${ }^{12}$ In addition, the appearance of new strains of COVID-19 possessing a higher rate of severe outcomes supports the need for vaccination of all healthcare personnel in preparation for an imminent spike in cases. The urgency of returning to the original vaccination strategy proposed by Mexico's GTAVCovid-19 group cannot be overemphasized.

The latest information on health personnel's vaccination was published on May 16th, a month after the teachers' vaccination program began. The report informed that a total of 1,097,190 healthcare providers had been vaccinated compared to 1,843,832 educational workers. ${ }^{13}$ A graphic description of available data comparing these to populations is presented in Figure 1. Unfortunately, there is no information regarding the proportion of health personnel vaccinated. However, it is estimated that $87 \%$ of the educational workers received at least one dose. ${ }^{14}$ Overall, as of August 18th, 23.19\% of Mexico's population had been fully vaccinated, including healthcare providers who had to wait in line for their vaccination turn according to age group. ${ }^{15}$ Currently, Mexico remains the leading country on health personnel deaths due to COVID-19 infection and faces a third pandemic wave with cases rising to 22,000 daily, most seen in the young and in the unvaccinated. ${ }^{16}$

The possible framing of vaccination as a political tool takes it out of the realm of medical science altogether. Instead, a successful vaccination program should be built around scientific data, public health benefits and an aim for full population coverage. The remaining should prevail in nations with limited resources, where the latter cannot be immediately fulfilled. ${ }^{17}$

The federal government in Mexico has ignored its own technical advisory group's strategic advice and international recommendations to vaccinate all healthcare personnel, regardless of their place of employment (public or private sector), thereby neglecting a considerable proportion of health workers. Therefore, it is essential to share various vaccination experiences so that other nations may be able to optimize their strategies and achieve success in overcoming this pandemic.

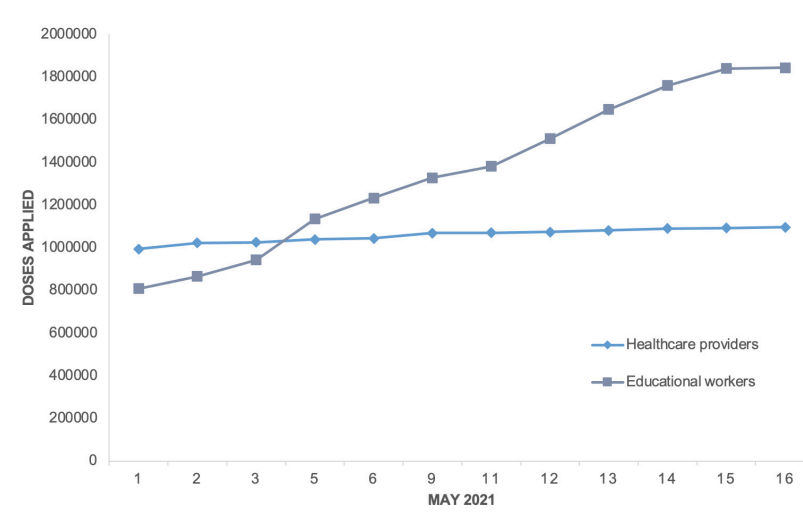

Figure 1. Cumulative COVID-19 vaccines applied during the first 16 days of May 2021 to healthcare providers compared to educational workers.

\section{ACKNOWLEDGEMENTS}

We would like to thank all Mexican healthcare workers who directly or indirectly contributed to the care of patients, and the support and maintenance of the health system during the pandemic.

\section{CONFLICT OF INTERESTS}

The authors completed the ICMJE Unified Competing Interest form (available upon request from the corresponding author), and declare no conflicts of interest.

\section{DISCLAIMER}

Authors hold sole responsibility for the views expressed in the manuscript, which may not necessarily reflect the opinion or policy of the Journal.

\section{AVAILABILITY OF DATA AND MATERIALS}

All data relevant to the study are included in the article. However, study materials and data that support the findings in this paper are available upon reasonable request by contacting the corresponding author.

\section{FUNDING}

No funding was obtained for this study.

\section{AUTHORS’ CONTRIBUTIONS}

All authors have contributed to each stage of the manuscript design and preparation, and approved the final version. All authors agree to be accountable for all aspects of the work.

\section{CORRESPONDENCE}

Michel F. Martinez Resendez, Tec de Monterrey, Monterrey, Mexico. Av. Batallon de San Patricio \#112. Col. Real de San Agustin, N.L. CP. 66278 Mexico; tel: +52 (81) 88880551 , 
fax: +52 (81) 88880551; drmichelfernando@gmail.com

2021 CET

Submitted: September 28, 2021 CET, Accepted: October 05, mons.org/licenses/by/4.0/legalcode for more information. 


\section{REFERENCES}

1. Institute for Global Health Sciences. University of California San Francisco. Mexico's Response to COVID-19: A Case Study. https://globalhealthscience s.ucsf.edu/sites/globalhealthsciences.ucsf.edu/files/m exico-covid-19-case-study-english.pdf. Published 2021. Accessed July 22, 2021.

2. Tatar M, Shoorekchali JM, Faraji MR, Wilson FA. International COVID-19 vaccine inequality amid the pandemic: Perpetuating a global crisis? J Glob Health. 2021;11(03086). doi:10.7189/jogh.11.03086

3. Barrágan S. México aparece en el lugar 10 a nivel mundial en compra de vacunas contra Covid-19. Aristegui Noticias. https://aristeguinoticias.com/230 2/mexico/mexico-pidio-a-paises-no-acaparar-vacuna s-y-es-uno-de-los-principales-compradores/. Published 2021. Accessed August 17, 2021.

4. Barrientos-Gutiérrez T, Alpuche-Aranda CM, Bautista-Arredondo S. Preguntas y respuestas sobre la estrategia de vacunación contra Covid-19 en México. Salud Publica Mex. 2021;63(2):167-169. http s://saludpublica.mx/index.php/spm/article/view/1251 1/12064. Accessed July 22, 2021.

5. Martinez F. Entre el 15 y 20 de abril iniciará vacunación de maestros: AMLO. La Jornada. https://w ww.jornada.com.mx/notas/2021/04/09/politica/entreel-15-y-20-de-abril-iniciara-vacunacion-de-maestro s-amlo/. Published 2021. Accessed July 22, 2021.

6. Mutambudzi M, Niedzwiedz C, Macdonald EB, et al. Occupation and risk of severe COVID-19: Prospective cohort study of 120075 UK Biobank participants. Occup Environ Med. 2021;78(5):307-314. doi:10.1136/ oemed-2020-106731

7. Organización Panamericana de la Salud / Organización Mundial de la Salud. Actualización epidemiológica: Enfermedad porCoronavirus (COVID-19). https://iris.paho.org/bitstream/handle/1 0665.2/53378/EpiUpdate9February2021_spa.pdf?sequ ence $=2$ \&isAllowed $=\mathrm{y}$. Published 2021. Accessed July $22,2021$.

8. Johansson MA, Quandelacy TM, Kada S, et al. SARS-CoV-2 Transmission from People without COVID-19 Symptoms. JAMA Netw Open. 2021;4(1):1-8. doi:10.1001/jamanetworkopen.2020.35 $\underline{057}$
9. Agren D. Understanding Mexican health worker COVID-19 deaths. Lancet. 2020;396(10254):807. doi:1 $\underline{0.1016 / \mathrm{s} 0140-6736(20) 31955-3}$

10. Rudan I. This is who to blame for the COVID-19 pandemic. J Glob Health. 2021;11:03035. doi:10.7189/i ogh.11.03035

11. INEGI. Disponibilidad y uso de tecnologías de la información y comunicaciones. https://www.inegi.or g.mx/temas/ticshogares/. Published 2020. Accessed July 22, 2021.

12. Bleier BS, Ramanathan M Jr, Lane AP. COVID-19 Vaccines May Not Prevent Nasal SARS-CoV-2 Infection and Asymptomatic Transmission. Otolaryngol Head Neck Surg. 2021;164(2):305-307. do i:10.1177/0194599820982633

13. Secretaria de Salud de México. COVID-19 MÉXICO Comunicado Técnico Diario. Gobierno de México. htt ps://www.gob.mx/cms/uploads/attachment/file/63763 8/CP_Salud_CTD_coronavirus_COVID-19_15may21.p df. Published 2021. Accessed August 18, 2021.

14. Secretaria de Salud de México. Invita Delfina Gómez Álvarez a madres, padres de familia y a tutores a ser parte del regreso a clases presenciales. Boletín No. 116. https://www.gob.mx/sep/es/articulos/boleti n-no-116-invita-delfina-gomez-alvarez-a-madres-pa dres-de-familia-y-a-tutores-a-ser-parte-del-regresoa-clases-presenciales?idiom=es. Published 2021. Accessed August 18, 2021.

15. Mathieu E, Ritchie H, Ortiz-Ospina E, et al. A global database of COVID-19 vaccinations. Nat Hum Behav. 2021;5(7):947-953. doi:10.1038/s41562-021-01 122-8

16. Martine-Valle A, Marie-Knaul F. Mexico, facing its third COVID-19 wave, shows the dangers of weak federal coordination. The Conversation. https://theco nversation.com/mexico-facing-its-third-covid-19-wa ve-shows-the-dangers-of-weak-federal-coordinatio n-164995. Published 2021. Accessed August 18, 2021.

17. Tatar M, Wilson FA. The largest vaccination campaign in history: A golden opportunity for bundling public health interventions. J Glob Health. 2021;11:03076. doi:10.7189/jogh.11.03076 